\title{
Hemşirelik Eğitiminde Simülasyonun Kullanımı: Sistematik İnceleme*
}

\author{
Use of Simulation in Nursing Education: A Systematic Review
}

\author{
Merdiye ŞENDIR**, Pınar DOĞAN***
}

İletişim/Correspondence: Merdiye ŞENDİR Adres/Address: İstanbul Üniversitesi Florence Nightingale Hemşirelik Fakültesi, Abide-i Hürriyet Caddesi, Şişli/İstanbul Tel: 021244000 00/ 27134 E-mail: msendir@istanbul.edu.tr

\begin{abstract}
$\ddot{O} Z$
Amaç: Bu sistematik inceleme, hemşirelik eğitiminde simülasyon kullanımının sonuçlarını değerlendiren çalışmaları sistematik olarak incelemek amactyla planlanmıștır.

Yöntem: Çalışmanın evrenini Nisan-Temmuz 2013 tarihinde "CINAHL Plus", "Medline”, "Health Source: Nurse/Academic Edition" veri tabanlart ile "Google Scholar" ve "Networked Digital Library of Theses and Dissestations" tez kaynaklartndan taranarak ulaşılan 545 makale oluşturmuştur. Incelemede "simulation", "nursing education" ve "simulation in nursing" anahtar kelimeleriyle son on yılda yayınlanmış (Nisan 2003- Temmuz 2013), yayın dili Türkçe ya da Ingilizce olan ve tam metni bulunan makaleler seçilmiştir. Bu makalelerden araştırma kriterlerini karşılayan toplam 15 çalışma incelemenin örneklemini oluşturmuştur.

Bulgular: Hemşirelik eğitiminde simülasyon kullanımına ilişkin çalışmaların sistematik incelemesi, bilgi-beceri ve eleştirel düşünme-klinik karar vermeyi değerlendiren araştırmalar olarak iki grup altında gerçekleştirilmiştir. Çalışmaya dahil edilen makalelerde deneysel, yarı deneysel ve tanımlayıcı-ilişki arayıcı araştırma tasarımlarının kullanıldığı saptanmıştır. Araştırmaların 7 'sinde, hemşirelik bilgi ve becerilerinin kazandırılmasında simülasyon ile ĕgitimin etkili olduğu belirlenmiştir. Ayrıca 10 araştırmada da simülasyon ile eğitimden sonra ögrencilerin, eleştirel düşünme, öz etkililik ve öz güven düzeylerinde artma saptanmiştır.
\end{abstract}

Sonuç: Hemşirelik eğitiminde simülasyonun, ögrenciye bilgi ve beceri kazandırmasının yanı sıra eleştirel düşünme, öz etkililik ve öz güvenin de gelişmesine katkı să̆layan bir ögrenme yöntemi olduğu görülmektedir.

Anahtar Kelimeler: Hemşirelik eğitimi, simülasyon, hemşirelikte simülasyon.

\section{ABSTRACT}

Aim: This systematic review is planned to investigate systematically the studies that evaluated the results of the use of simulation in nursing education.

Method: The population of this study is consisted of 545 articles from accessed by searching on "CINAHL Plus", "Medline", " Health Source: Nurse / Academic Edition" and "Google Scholar" databases and "Networked Digital Library of Theses and Dissestations" sources in dates between April a July 2013. In this review, the articles were selected as full text by searching with "simulation", "nursing education" and "simulation in nursing" key words and they were published in English and Turkish languages in the last decade (April 2003-July 2013).Total 15 studies of these articles that meet the research's criteria have occurred the sample of the review.

Results: Systematic review of the studies that evaluated simulation in nursing education were divided into two groups as studies that are evaluating the knowledge-skills and critical thinking-clinical decision making. In this review, experimental, quasiexperimental and descriptive-correlational research designs were used often for the studies. In the seven researches, simulation training have been identified to be effective in gaining of nursing knowledge and skills. Also, in ten studies, were determined an increase the level of student's critical thinking, self-efficacy and self-confidence, after training with simulation.

Conclusion: The simulation in nursing education, is observed a learning method is contributing to the development critical thinking, self efficacy and self confidence besides gaining knowledge and skills to students.

Key Words: Nursing education, simulation, simulation in nursing.

* 14. Ulusal Hemşirelik Kongresi’nde sözlü bildiri olarak sunulmuştur (25-27 Ekim 2013, Muğla), **Doç. Dr. İstanbul Üniversitesi Florence Nightingale Hemşirelik Fakültesi, **ö̈̆rr. Gör. İstanbul Medipol Üniversitesi

Yazının gönderilme tarihi: 22.08.2014

Yazının basım için kabul tarihi: 15.01.2015 


\section{GíRiş}

Hemşirelik, kuramsal içeriğin, pratik beceri ile anlam11 bir biçimde birleşmesini gerektiren uygulamalı bir meslektir. Hemşirelik eğitimi sürecinde, öğrencilerin kendi disiplinlerine ilişkin bilgi, beceri, tutum, mesleki değer ve etik standartları içselleştirmesine ve bunları davranışlarının bir parçası haline getirmesine katkı sağlanmalıdır (Boztepe ve Terzioğlu 2013).

Hemşirelik eğitiminde, öğrencilerin psikomotor ve bilişsel becerileri öğrenme etkinliklerinin güçlendirilmesi amacıyla çeşitli öğretim araçları kullanılmaktadır. $\mathrm{Bu}$ araç gereçler öğrencinin dikkatini arttırırken, eğitimi monotonluktan kurtarmakta ve öğrencinin aktif katılımını sağlayarak öğretimin kalıcılığ1nı sağlamaktadır. Yapılan araştırmalara göre okunanların \%10'u, işitilenlerin \%20'si, görülenlerin \%30’u kalıcı olurken, görülen, işitilen, söylenen ve yapılanların ise \%90'1 kalıcı olmaktadır (Hannafin ve Foshay 2006; Karaduman 2008; Yalın 2004).

Hemşirelik eğitiminde öğrencilerin becerilerini geliştirmeye yönelik öğretim araç gereçleri belirlenirken; seçilen aracın hedeflere uygun olması, öğrencilere kazanımlarını uygulama imkanı vermesi gerekmektedir. Eğitimcilerin, kullanacağı araçları fonksiyonel, ilgi çekici, dayanıklı, eldeki imkanlar dahilinde en zengin uyarıcılarla donatılmış öğrenme ortamı oluşturacak şekilde seçmeleri son derece önemlidir (Hacıalioğlu 2011). Seçilecek öğretim araç ve gereçleri öğrencilerin bilişsel, psikomotor ve sosyal gelişim düzeyine uygun olmalı ve bu gelişim alanlarına katkı sağlayıcı özellikler taşımalıdır (Karaduman 2008).

Günümüzde sağlık bakım sisteminin karmaşı yapısı içinde klinik uygulama alanlarının sınırlı olması, hastaların hastanede kalış sürelerinin kısalması ve eğitim sistemi kaynaklı nedenlerle klinikte daha az zaman geçirmeleri sonucunda öğrencilerin uygun klinik deneyim kazanabilmeleri her zaman mümkün olamamaktadır (Rhodes ve Curran 2005). Ancak tüm bu olumsuz faktörlere rağmen hemşirelerden zor durumlar karş1sında hemşirelik becerilerini eksiksiz sergileyebile- cek yeteneğe sahip olmaları beklenmektedir. Söz konusu sinırlamalar göz önüne alındığında, simülasyon temelli öğrenme, sürekli değişen sağlık bakım sistemi içinde eğitim gören hemşirelik öğrencilerinin yeterli hazırlanmasında anahtar bir bileşendir (Norman 2012). Simülasyon uygulamaları, çevresel risklerin en aza indirildiği öğrenme ortamını sağlayarak sağlık bakım hizmetlerinde hastalara güvenli bakımın verilebilmesinde önemli bir adım olarak ele alınmaktadır. Simülasyona dayalı eğitimler her öğrencinin öğrenmesine firsat tanıyan, eşitlikçi, yetişkin öğrenme ilkelerinin etkili bir şekilde kullanıldığı, farklı öğrenme stillerine uygun ortamlardır. Bu ortamlarda ilgi ve gereksinimler öğrenen ve eğitici tarafından tanımlanmakta, öğrenen deneyimleri ön planda tutulmakta, yaparak öğrenmesine firsat tanınmakta ve geribildirimlerle desteklenmektedir. 2003 yılından bu yana, Amerika'da Ulusal Hemşireler Birliği (NLN) tarafından öğrencilerin karmaşık bir klinik çevreye hazırlanmasının yanı sıra eleştirel düşünmeye dayalı ve gerçek yaşam durumlarının deneyimlendiği gerçekçi bir öğretim ortamı oluşturulması için de simülasyonların kullanımı desteklenmektedir (Fowler-Durham ve Alden 2007; Sanford 2010). Ülkemizde de 2010 yılından günümüze hemşirelik eğitiminde simülasyonun etkili bir öğrenme ve öğretim metodu olarak kullanımı giderek yaygınlaşmaktadır.

Son yıllarda gerçekliğe yakınlığı yüksek insan simülatörleri hemşirelik eğitiminde bir eğitim aracı olarak giderek artan bir ilgiyle kullanılır hale gelmekle birlikte beraberinde çeşitli soruları da getirmektedir. Hemşirelikte simülasyon yeni bir teknoloji mi? Simülasyon ile hemşirelik eğitiminde pozitif öğrenme çıtıları oluşabilir mi? Simülasyonun hemşirelik eğitiminde kullanılmasıyla öğretimin etkinliğine katkısını ortaya koyan kanıt temelli araştırmalar var mı?

Hemşirelik eğitiminde simülasyon uygulamalarının sonuçlarını/etkinliğini değerlendiren çalışmalar gittikçe artmaktadır. Ancak bu çalışmaların sonuçlarının incelenerek ortak sonuçların gösterildiği sistematik inceleme çalışmaları yetersizdir. Bu bağlamda bu çalışma, 
hemşirelik eğitiminde simülasyon kullanımını incelemeye yönelik yapılan çalışmaları analiz etmek ve araştırmacılara somut veri sunmak amacıyla planlanmıştır.

\section{YÖNTEM}

\section{Araştırma Kriterleri}

Çalışma kapsamına alınacak makalelerin seçiminde aşağıdaki kriterler dikkate alınmıştır;

- Hemşirelik eğitiminde simülasyon kullanımının sonuçlarını değerlendiren araştırma olması,

- Araştırma verilerinin toplanmasında insan hasta simülatörleri (HPS), gerçekliğe yakınlığı yüksek/orta insan simülatörleri (HFS, LPS), video simülasyon ve standardize/simüle hasta simülasyon yöntemlerinin kullanılmış olması,

- Lisans ve lisansüstü hemşire öğrencilere odaklanan araştırma olması,

- Yayın dilinin Türkçe ya da İngilizce olması,

- Son on yılda yayınlanmış (2003-2013) olması,

- Tam metnine ulaşılabilmesi.

Araştırma tasarımı açısından bir sınır konulmamış bilgisayar temelli simülasyon ve anatomik modellerle yapılmış araştırmalar çalışma kapsamına alınmamıştır.

\section{Çalışmaların Araştırılması ve Seçilmesi}

\section{Örneklem Tanımı}

Çalışmalar; Nisan-Temmuz 2013 tarihinde "simulation", "nursing education" ve "simulation in nursing" anahtar kelimeleri ile "CINAHL Plus", "Medline", "Health Source: Nurse/Academic Edition" veri tabanlar1 ile "Google Scholar" ve "Networked Digital Library of Theses and Dissestations" tezler taranarak seçilmiştir. Yükseklisans ve doktora tezleri, araştırma özetleri, araştırmaların tam metinleri, hemşirelik dergileri, biyomedikal dergileri ve yardımeı dergilerde yer alan veriler tercih edilmiştir. Elektronik arama ile saptanan ilgili tüm yazıların başlık ve özetleri, araştırmacılar tarafından bağımsız olarak gözden geçirilmiştir. Eğer başlık ya da özet açık değilse, çalışmanın dahil olma kriterlerine uyup uymadığının araştırılması için çalışmanın tam metni incelenmiştir. Araş- tırmacılar tarafından dahil edilmeyen çalışmaların dahil edilmeme nedenleri de kayıt edilmiştir (Tablo 1). Araştırmacıların incelemeleri daha sonra karşılaştırılmış ve dahil edilen 545 araştırmadan, inceleme dişında tutulma kriterleri dikkate alınınca 530 kaynak elenmiş, sistematik inceleme için 15 çalışmanın tam metinleri kaynak olarak alınmıştır. Seçilen makalelerin her biri hemşirelik eğitimi ve simülasyona temelli öğrenme ile ilişkili araştırmaları kapsamaktadır. Araştırmacılar arasında fikir anlaşmazlığı yaşanmamıştır.

Tablo 1. Sistematik İnceleme Kapsamına Alınan Araştırmaların Belirlenme Süreci

\begin{tabular}{|l|l|}
\hline \multicolumn{2}{|c|}{ Veri tabanlarının incelenmesi } \\
\hline \multicolumn{2}{|c|}{ Potansiyel ilişkili araştırmalar= 545 Araştırma makalesi } \\
\hline & İnceleme dışı tutulma \\
& nedenleri; \\
& - Belirlenen simülasyon \\
& yöntemlerinin dışıındaki \\
& yöntemlerle araştırılmış \\
Dahil edilmeyen & olması \\
çalışmalar=530 & Orijinal araştırma \\
& makalesi olamaması \\
& - Tam metnine \\
& ulaşılamaması \\
& - Yayının son 10 yıl içinde \\
& yapılmış olmaması \\
\hline \multicolumn{2}{|c|}{ Dahil olma kriterlerine uyan çalışmalar=15 } \\
\hline
\end{tabular}

\section{Veri analizi}

Verilerin özetlenmesi için standart bir veri özetleme formu geliştirilmiş ve veriler buna göre değerlendirilmiştir. Birbirinden bağımsız olarak araştırmacılar tarafından dahil edilen çalışmalar, veri özetleme formuna göre özetlenmiştir. Daha sonra özetler karşılaş̧trılmış ve araştırmacılar arasında fikir birliği oluşturulmuştur.

Veri özetleme formunun içeriğinde;

- Çalışmanın yazarları ve yılı,

- Çalışmanın amacı,

- Araştırma tasarımı,

- Örneklem büyüklüğü,

- Araştırmanın bağımlı değişkenleri,

- Araştırmanın bulguları,

- Araştırmanın kuramsal çerçevesi yer almıştır. 


\section{Araştırmanın Sınırlılıkları}

$\mathrm{Bu}$ sistematik inceleme, iki araştırmacı tarafından yapıldı ğından, kriterlerin belirlenmesi, araştırma metodolojisi ve bulguların analizinde yan tutma tavrı gelişmiş olabilir. Sistematik incelemenin daha fazla araştırmacı tarafından yapılmasının daha iyi olacağ1 düşünülmektedir. Sistematik incelemede, literatürün araştırılmasında daima yetersizlik tehdidi olduğundan ve araştırmada eldeki imkanlar dahilinde literatüre ulaşmaya çalışıldığından araştırma için geçerli sonuçlar içeren çalışmalara ulaşılamamış olabilir. İncelenen araştırmaların bir kısmında örneklem sayılar1 yetersiz olduğu için verilerin analizi ile ilgili sınırlilıklar mevcuttur.

\section{BULGULAR}

Bu sistematik inceleme çalışmasında, 2003-2013 yılları arasında yayınlanan 15 çalışma yer almaktadır. İncelenen araştırmaların türü, örneklem özellikleri, bulguları ve sonuçları Tablo 2'de özetlenmiştir. Çalışmaların çoğunluğu tanımlayıcı-ilişki arayıcı, ön test-son test kontrollü yarı deneysel veya deneysel araştırma tasarımlarından oluşmaktadır. On beş çalışmada toplam 1896 katılımcı yer almıştır. İncelemede yer alan araştırmalar, öğrencilerin bilgi ve becerilerini değerlendiren ve öğrencilerin eleştirel düşünme, öz etkililik, iletişim ve klinik karar verme, ekip çalışması, memnuniyet, öz güven düzeylerini değerlendiren çalışmalar olmak üzere iki ana başlık altında incelenmiştir.

\section{Bilgi-Beceri Değerlendirme}

Sistematik inceleme kapsamında; 15 çalışmanın dokuzunda simülasyon temelli öğrenme yöntemi sonrasında öğrencilerin kendine güven düzeyi, bilgi ve becerilerinin gelişiminde istatistiksel olarak anlamlı bir artış olduğu belirlenmiş̧tir (Alinier ve ark. 2006; Bornais ve ark. 2012; Butler, Weltre ve Brady 2009; Jeffries ve Rizzolo 2006; Kim-Godwin ve ark. 2013; Reid-Searl ve ark. 2012; Rodgers, Securro ve Pauley 2009; Smith ve Roehrs 2009; Tosteruda, Hedelin ve Hall-Lord 2013). Bu grupta incelenen çalışmaların beşinde örneklem sayısı açısından sınırlılık olduğu görülmüştür
(Bornais ve ark. 2012; Butler ve ark. 2009; Flude, Keates ve Larocque 2012; Reid-Searl ve ark. 2012; Rodgers ve ark. 2009). Gerçekliğe Yakınlığı Yüksek Simülasyon Yönteminin etkinliğinin değerlendirildiği Jeffries ve Rizzolo'nun çalışmasının örneklem sayısı en fazla olan çalışma olduğu görülmüştür. Bilgi ve beceri değerlendirilmesine yönelik ele alınan araştırmaların ikisinde ön test-son test yöntemi kullanılmıştır (Alinier ve ark. 2006; Jeffries ve Rizzolo 2006).

\section{Öz-Etkililik, Memnuniyet ve Öz-Güven Düzeylerini, Eleştirel Düşünme ve Klinik Karar Verme Becerilerini Değerlendirme}

$\mathrm{Bu}$ kapsamda incelenen araştırmaların dördünde simülasyon uygulamalarının kullanılmasıyla öğrencilerin eleştirel düşünme beceri düzeylerinde artış olduğu sonucuna ulaşılmaktadır (Bambini, Washburn ve Perkins 2009; Fero ve ark. 2010; Smith ve Roehrs 2009; Sullivan-Mann, Perron ve Fellner 2009). Araştırma sonuçlarına göre üç çalışmada simülasyon yönteminin kullanılmasıyla hemşirelik öğrencilerinin öz etkililik düzeylerinde gelişme görülmektedir (Bambini ve ark. 2009; Flude ve ark. 2012; MacConville ve Lane 2005). Bu becerilerin yanı sira incelenen çalışmalar simülasyon temelli öğrenme yönteminin memnuniyet, karar verme ve problem çözme gibi yeterliliklerin de artmasında etkili bir yöntem olduğunu göstermektedir (Butler ve ark. 2009; Flude ve ark. 2012; Fountain ve Alfred 2009; Jeffries ve Rizzolo 2006; Kim-Godwin ve ark. 2013; Reid-Searl ve ark. 2012; Smith ve Roehrs 2009; Tosteruda ve ark. 2013).

İncelenen iki araştırma sonucunda HPS yöntemiyle yapılan eğitim sayesinde hemşirelik öğrencilerinin doğum sonu ve ameliyat sonu bakımda öz güven düzeylerinin istatistiksel olarak anlamlı düzeyde arttığ belirlenmiştir (Bambini ve ark. 2009; Jeffries ve Rizzolo 2006).

Sistematik inceleme sonucunda araştırmalar eğitim girişimleri açısından ele alındığında; araştırmaların dokuzunda orta ve yüksek derecede gerçekliğe yakın in- 
san simülatörleri, klasik eğitim yöntemleriyle karşılaştırılarak simülasyon uygulamalarında tercih edilmiştir (Alinier ve ark. 2006; Butler ve ark. 2009; Jeffries ve Rizzolo 2006; Fero ve ark. 2010; Flude ve ark. 2012; Fountain ve Alfred 2009; Reid-Searl ve ark. 2012; Rodgers ve ark. 2009; Tosteruda ve ark. 2013). İncelenen çalışmaların ikisinde standardize/simüle hasta yöntemiyle araştırma bulguları elde edilmiştir (Bornais ve ark. 2012; Flude ve ark. 2012). Diğer araştırmalarda öğrencilerin video simülasyon, vaka çalışması, rol oynama, yapılandırılmış klinik deneyim gibi yöntemlerle simülasyon uygulama performansları göstermeleri sağlanmıştır (Fero ve ark. 2010; Kim-Godwin ve ark. 2013; McConville ve Lane 2005; Smith ve Roehrs 2009).

\section{TARTIŞMA}

Temel hemşirelik eğitiminin içinde öğrencilerden hem teorik hem de pratik önemli becerileri kazanmaları beklenmektedir. Sistematik inceleme sonucunda; incelenen makaleler simülasyon uygulamalarının kontrollü simülasyon laboratuvarı ortamında yapıldığında öğrencilerin klinik beceri ve yeterlilik kazanmasının yanı sıra eleştirel düşünme ve öz güven düzeylerinin gelişmesine de katkı sağladığını göstermektedir (Alinier ve ark. 2006; Jeffries ve Rizzolo 2006).

İnceleme bulguları doğrultusunda, öğrencilerin bilgi düzeylerinin simülasyon temelli öğrenme deneyiminden sonra bazı çalışmalarda istatistiksel olarak anlam11 düzeyde olmasa da arttığ 1 görülmüştür. Simülasyon uygulamaları yeni bir bilginin öğretilmesinden ziyade var olan bilgilerin sentez edilmesinde kullanılan bir yöntem olarak kabul edildiği için bu durumun şaşırtıcı olmadığ 1 düşünülmektedir.

İncelenen araştırmalarda; objektif yapılandırılmış klinik sınav gibi bilgi ve becerilerin değerlendirilmesini sağlayacak yöntemlerin yanı sıra öğrencilerin klinik yargılama yeteneklerinin göstergesi olarak öğrenimden memnuniyet düzeyleri veya öğrenimden beklentilerinin belirleneceği dolaylı ölçümlerde yapılmıştır. Objektif yapılandırılmış klinik sınav, hemşirelik becerilerinin objektif olarak değerlendirilmesinde kullanılan en geçerli yöntem olarak değerlendirilmektedir (Bartfay ve ark. 2004).

Araştırma sonuçları incelendiğinde çeşitli konularda simülasyon ve benzer diğer interaktif eğitim yöntemlerinin (vaka çalışması, video simülasyon) karşılaştırmalı değerlendirmelerinin yapıldığı araştırmaların sayısının oldukça az olduğu belirlenmiştir $(n=4$, \%26). Bu konuda sonraki yıllarda yapilacak olan araştırmaların bu boşluğu kapatacağı düşünülmektedir.

Simülasyon temelli öğrenme yönteminin kullanılması bilgi ve beceri geliştirmenin yanında bilginin klinik alanda kullanılabilmesinde öğrenme sürecinin önemli bir parçası olan bilişsel becerilerin kazanılmasında da önemli bir yöntemdir. Bu inceleme sonuçları; simülasyon uygulamalarının hemşirelik eğitimi içinde kullanılması ile öğrencilerin bilgi düzeylerinin, beceri geliştirme düzeylerinin ve iletişim becerilerinin arttığını; ayrıca eleştirel düşünme, öz etkililik, öz güven, klinik öncesi deneyim düzeylerinin de gelişmesine katkı sağlandığını göstermektedir.

\section{SONUÇ VE ÖNERILLER}

Hemşirelik eğitimi ve simülasyon konusunda literatür incelendiğinde; simülasyonun bilgi, beceri, öz güven, eleştirel düşünme ve öz etkililik gibi becerilerin gelişmesine katkı sağlayan öğrenme ortamının yaratılmasında yararlı olduğu sonucuna ulaşılmaktadır. Bununla beraber simülasyon yöntemleriyle ulaşılan sonuçların klinik alana taşınmasıyla ilgili bir boşluğun oluştuğu görülmektedir. Bu konuda akademisyen ve klinik hemşirelerin işbirliği içinde olmalarıyla klinikte psikomotor ve bilişsel anlamda donanımlı hemşirelerin gelişmesine katkı sağlanacağı düşünülmektedir. $\mathrm{Bu}$ sistematik çalışmanın hemşirelik eğitimi ve simülasyona yönelik sonraki birçok araştırma için bir destek oluşturulacağı öngörülmektedir.

Simülatörlerin hemşirelik laboratuarlarında pahalı yatak işgalcileri haline gelmemeleri için daha fazla araştırmaya gereksinim vardır. 


\begin{tabular}{|c|c|c|c|c|c|c|c|}
\hline 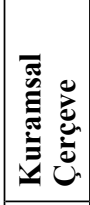 & 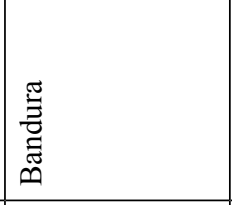 & 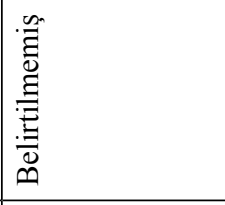 & 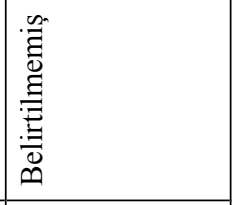 & 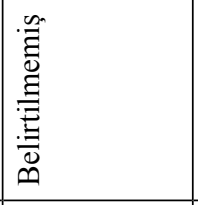 & 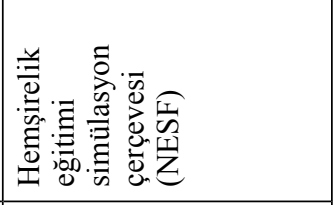 & 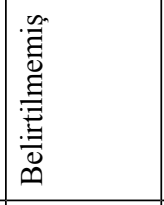 & 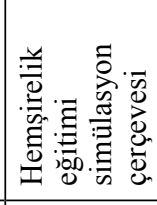 \\
\hline 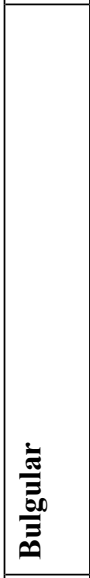 & 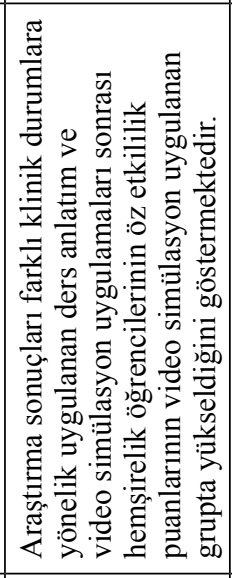 & 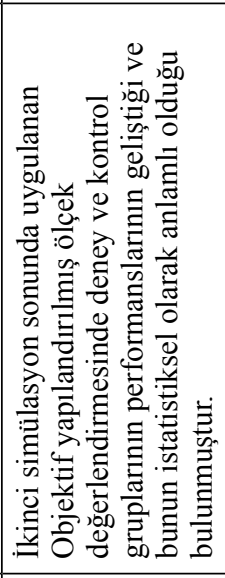 & 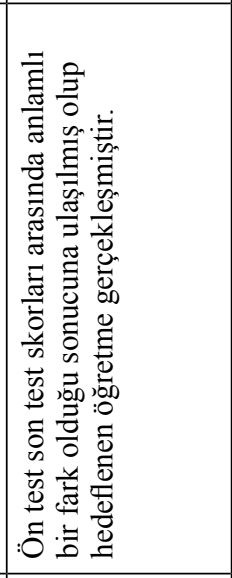 & 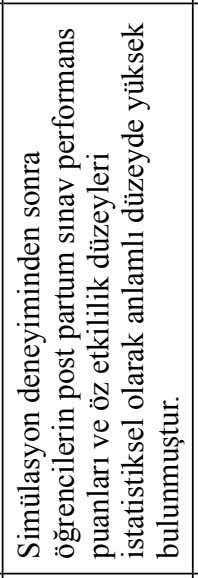 & 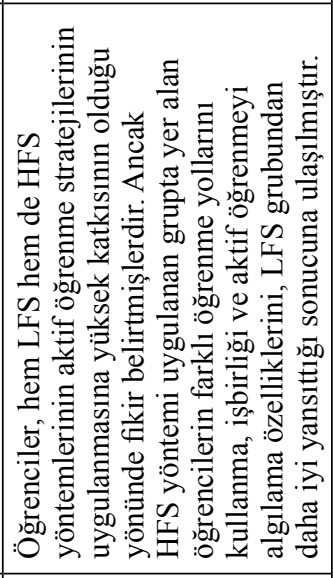 & 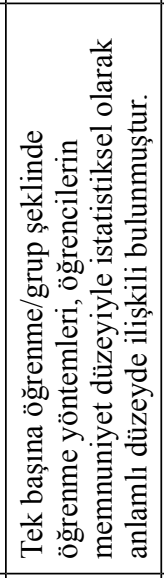 & 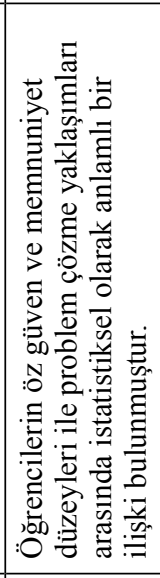 \\
\hline 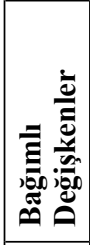 & 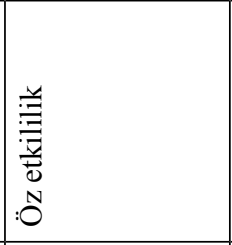 & 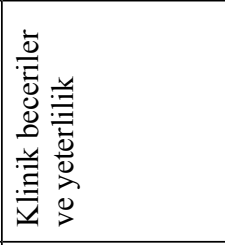 & 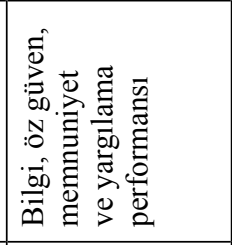 & 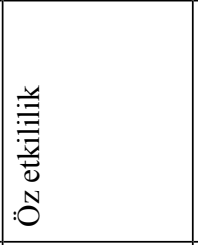 & 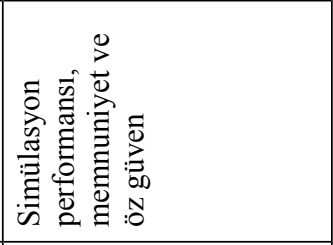 & 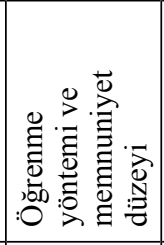 & 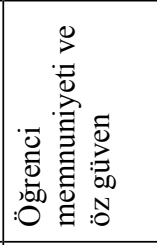 \\
\hline 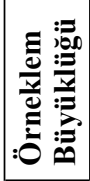 & 哭 & $\hat{\sigma}$ & $\stackrel{\infty}{2}$ & $\cong$ & $\bar{m}$ & 黾 & $\mathscr{\infty}$ \\
\hline 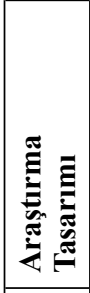 & 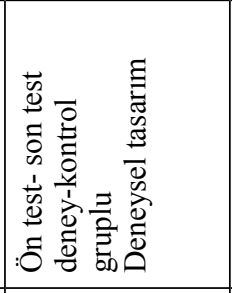 & 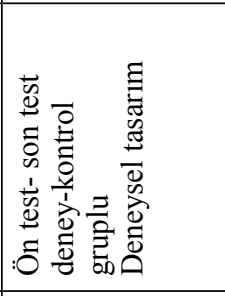 & 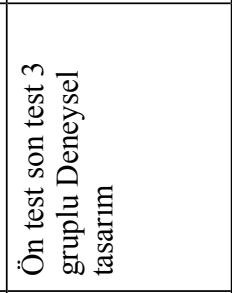 & 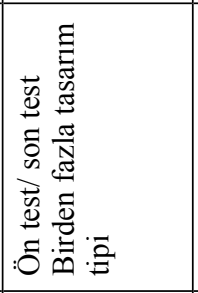 & 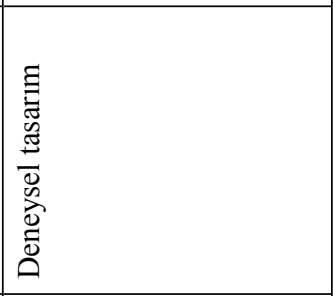 & 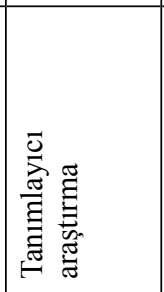 & 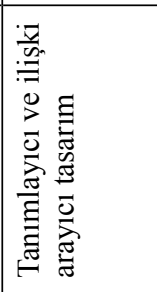 \\
\hline 崖 & 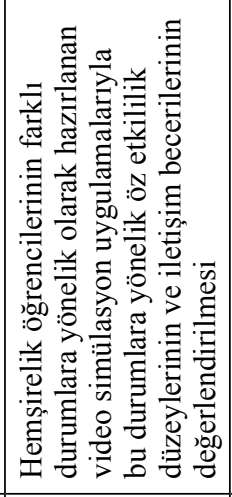 & 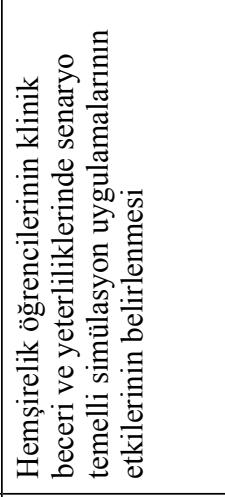 & 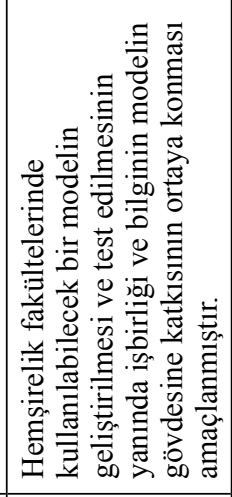 & 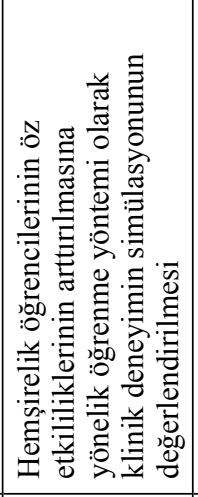 & 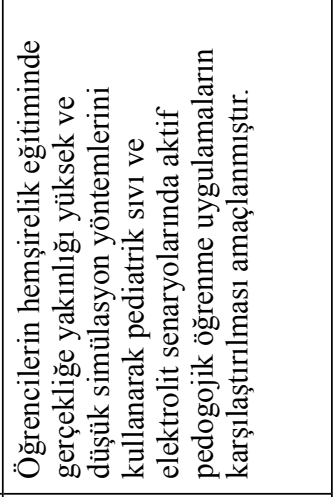 & 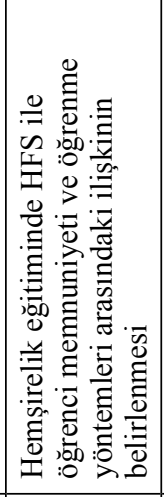 & 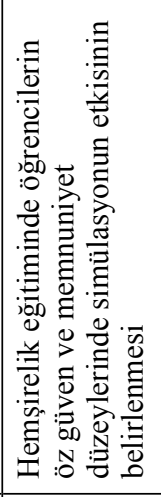 \\
\hline 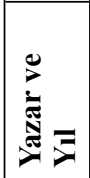 & 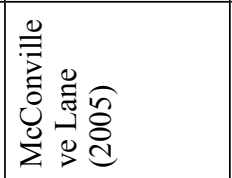 & 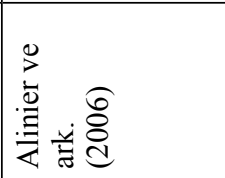 & 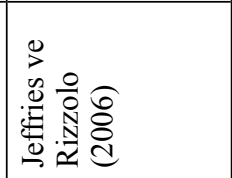 & 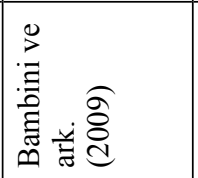 & 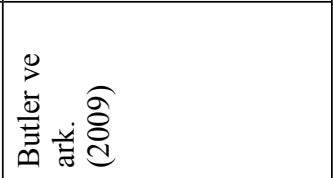 & 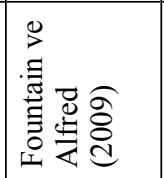 & 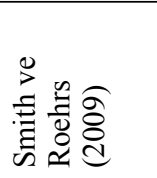 \\
\hline
\end{tabular}




\begin{tabular}{|c|c|c|c|c|c|c|c|c|}
\hline 焉 & 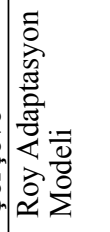 & 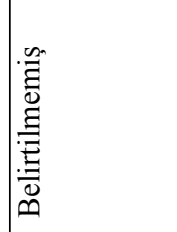 & 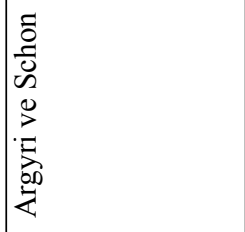 & 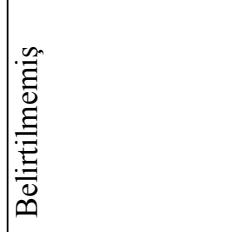 & 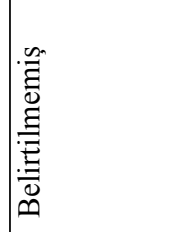 & 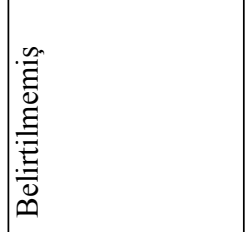 & 告 & 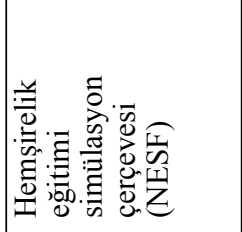 \\
\hline 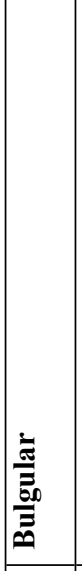 & 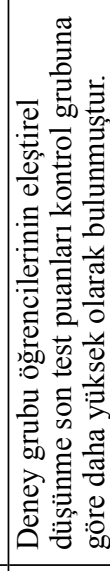 & 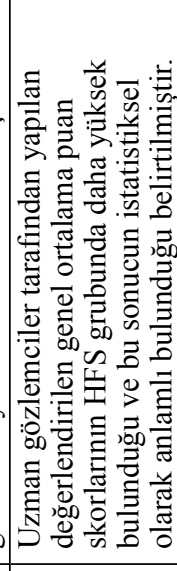 & 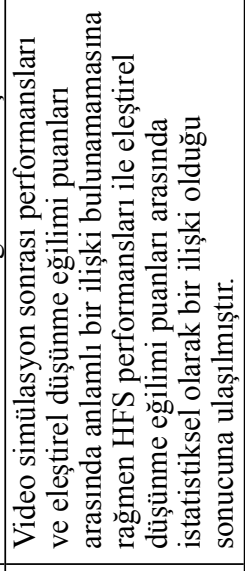 & 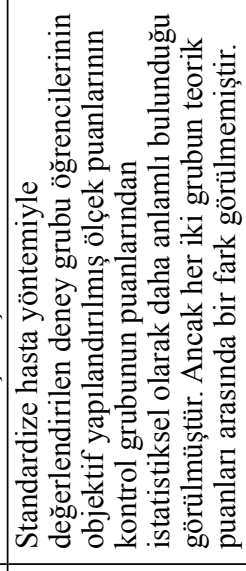 & 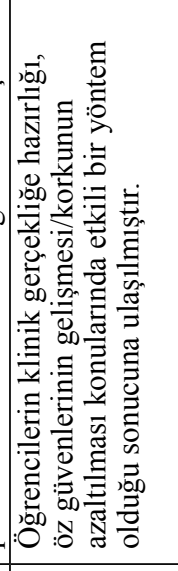 & 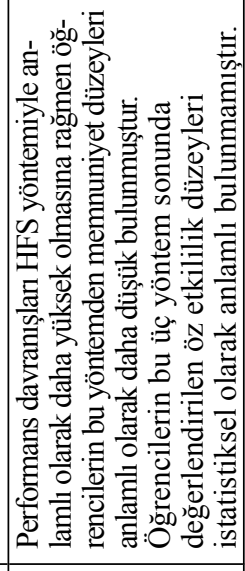 & 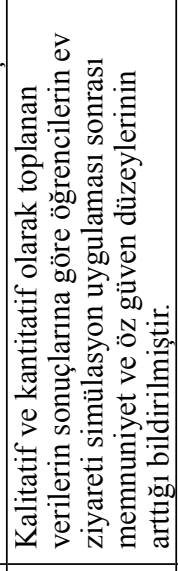 & 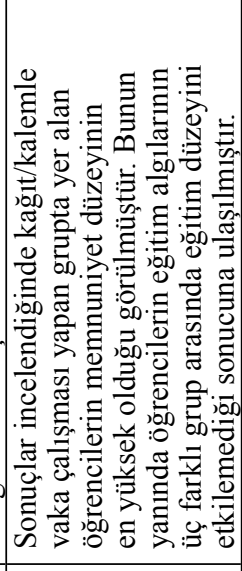 \\
\hline 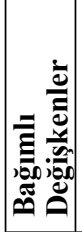 & 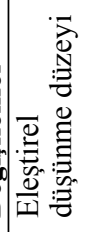 & 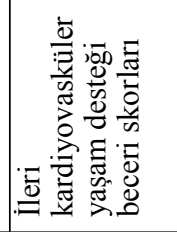 & 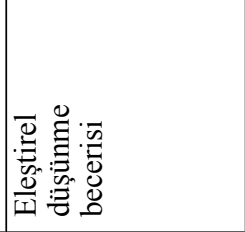 & 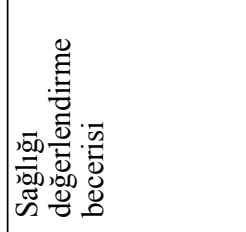 & 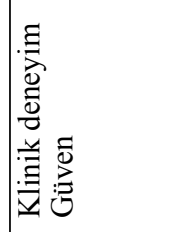 & 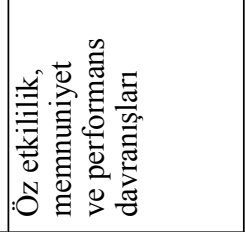 & 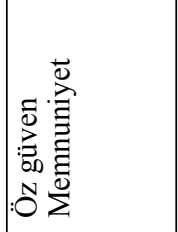 & 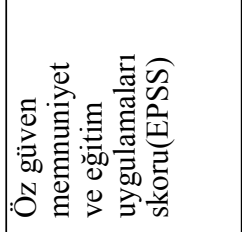 \\
\hline 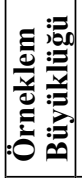 & & $\hat{n}$ & D & $\stackrel{\infty}{\circ}$ & $\bar{\sim}$ & $\forall$ & $\because$ & $\infty$ \\
\hline 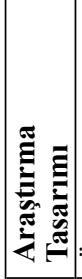 & 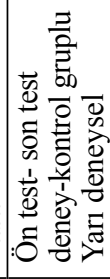 & 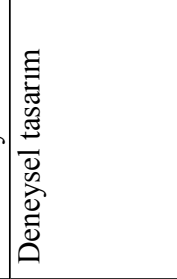 & 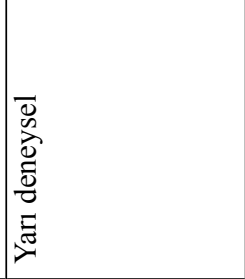 & 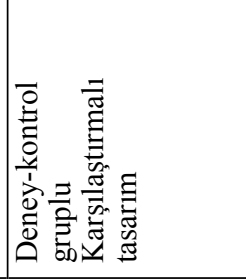 & 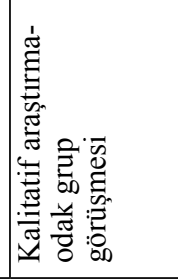 & 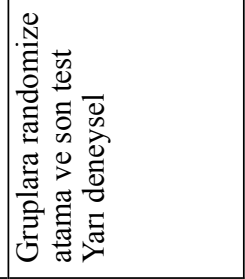 & 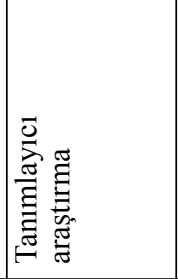 & 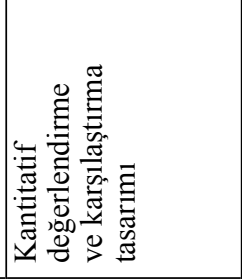 \\
\hline E & 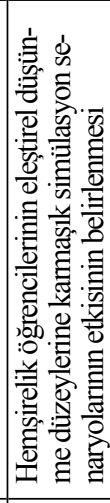 & 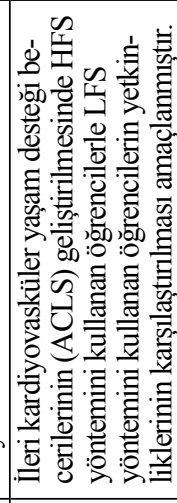 & 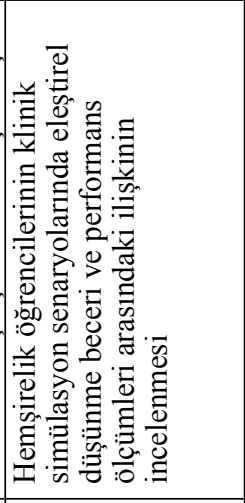 & 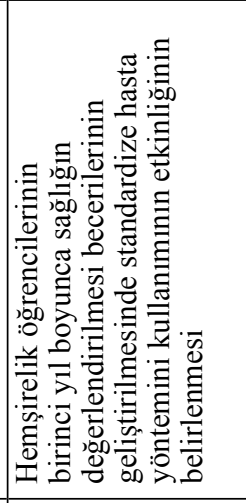 & 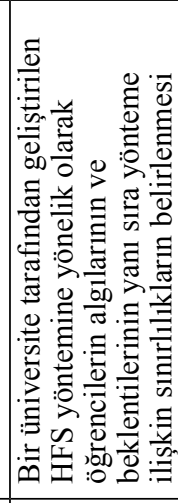 & 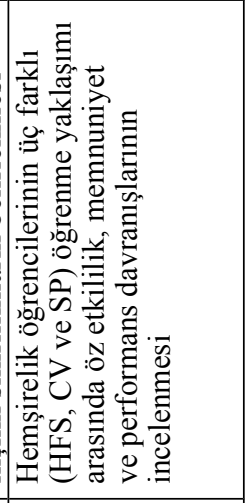 & 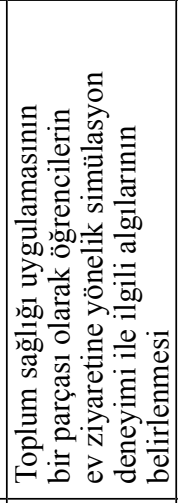 & 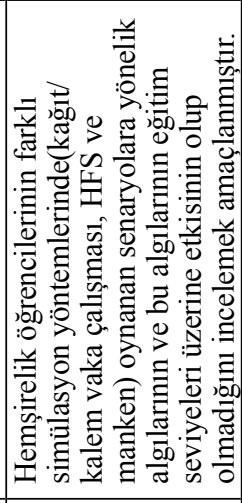 \\
\hline 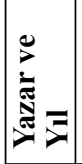 & 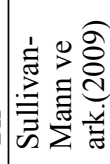 & 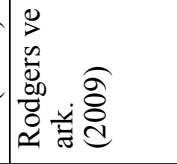 & 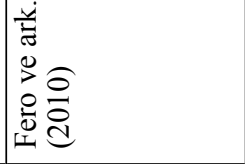 & 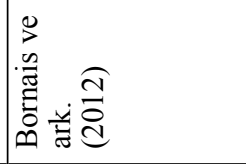 & 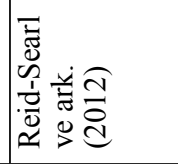 & 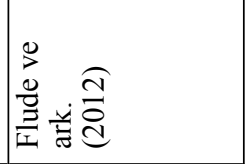 & 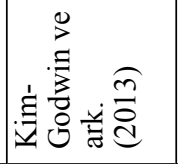 & 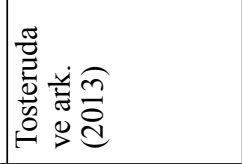 \\
\hline
\end{tabular}




\section{KAYNAKLAR}

Alinier, G., Hunt, B., Gordon, R., Harwood, C. (2006). Effectiveness of intermediate-fidelity simulation training technology in undergraduate nursing education. Journal of Advanced Nursing, 54(3): 359-369.

Bartfay, W., Rombough, R., Howse, E., LeBlanc, R. (2004). The OSCE approach in nursing education: Objective structured clinical examinations can be effective vehicles for nursing education and practice by promoting the mastery of clinical skills and decisionmaking in controlled and safe learning environments. The Canadian Nurse, 100(3): 18-23.

Bambini, D., Washburn, J., Perkins, R. (2009). Outcomes of clinical simulation for novice nursing students: Communication, confidence, clinical judgment. Nursing Education Perspectives, 30(2): 79-82.

Bornais, A. K., Janet, E., Ryan, E., El-Masri, M. M. (2012). Evaluating undergraudate nursing students' learning using standardized patients. Journal of Professional Nursing, 28(5): 291-296.

Boztepe, H., Terzioğlu, F. (2013). Hemşirelik eğitiminde beceri değerlendirme. Anadolu Hemşirelik ve Sağlık Bilimleri Dergisi, 16(1): 57-63.

Butler, K.W., Veltre, D. E., Brady, D. (2009). Implementation of active learning pedagogy comparing low-fidelity simulation versus high-fidelity simulation in pediatric nursing education. Clinical Simulation in Nursing, 5: 129-136.

Fero, L. J. ver ark. (2010). Critical thinking skills in nursing students: Comparison of simulation-based performance with metrics. Journal of Advanced Nursing. 66(10): 2182-2193.

Flude, L. M., Keates, W. B., Larocque, M. (2012). Evaluating highfidelity human simulators andstandardized patients in an undergraduate nursing health assessment course. Nursing Education Today, 32: 448-452.

Fountain, R. A., Alfred, D. (2009). Student satisfaction with highfidelity simulation: Does it correlate with learning styles? Nursing Education Perspectives, 30(2): 96-98.

Fowler-Durham, C., Alden, K. (2007). Enhancing patient safety in nursing education through patient simulation. Hughes, R. G. (Ed.). Patient Safety and Quality: An Evidence-Based Handbook for Nurses. Rockville MD., US, 3-221.

Hacialioğlu, H. (2011). Hemşirelikte Öğretim Öğrenme ve Ĕgitim. Nobel Tip Kitabevleri, İstanbul.

Hannafin, R. D., Foshay, W. R. (2006). Computer based instruction $(\mathrm{CBI})$ rediscovered role in KF12: An evaluation case study of one high school's use of CBI to improve pass rates on high stakes tests. Educational Technology Research and Development, 56(2): 147-160.

Jeffries, P. R., Rizzolo, M. A. (2006). Designing and Implementing Models for the Innovative Use of Simulation to Teach Nursing Care of Ill Adults and Children: A National, Multi-Site, Multi-Method Study. National League for Nursing, New York.

Karaduman, B. (2008). İlköğretim 6. sınıf fen ve teknoloji dersi "maddenin tanecikli yapısı" ünitesinin öğretiminde bilgisayar destekli ve bilgisayar temelli öğretim. Yüksek Lisans Tezi, Çukurova Üniversitesi Sosyal Bilimler Enstitüsü, Adana.

Kim-Godwin, Y. S. ve ark. (2013). Students like peer evaluation during home visit simulation experiences. Clinical Simulation in Nursing, 9: 535-542.

McConville, S. A., Lane, A. M. (2006). Using on-line video clips to enhance self-efficacy toward dealing with diffucult situations among nursing students. Nursing Education Today, 26: 206-208.

Norman, J. (2012). Systematic review of the literature on simulation in nursing education. ABNF Journal, 23(2): 24-29.

Reid-Searl, K., Happell, B., Vieth, L., Eaton, A. (2012). High fidelity patient silicone simulation: A qualitative evaluation of nursing students' experiences. Collegian, 19: 77-83.

Rhodes, L. M., Curran, C. (2005). Use of the human patient simülatör to teach clinical judgment skills in a baccalaureate nursing program. Computer Informatics Nursing, 23(5): 256-262.

Rodgers, D. L., Securro, S. J., Pauley, R. D. (2009). The effect of high-fidelity simulation on educational out comes in an advanced cardiovascular life support course. Simulation in Healthcare, 4(4): 200-206.

Sanford, P. G. (2010). Simulation in nursing education: A rewiew of the research. The Qualitative Report, 15(4):1006-1011.

Smith, S. J., Roehrs, C. J. (2009). High-fidelty simulation: Factors correlated with nursing student satisfaction and self-confidence. Nursing Education Perspectives, 30: 74-78.

Sullivan-Mann, J., Perron, C. A., Feliner, A. N. (2009). The effects of simulation on nursing students' clinical thinking scores: A quantitative study. Newborn\&Infant Nursing Rewiews, 9(2):111-116.

Tosterud, R., Hedelin, B., Hall-Lord, M. L. (2013). Nursing students' perceptions of high- and low-fidelity simulation used as learning methods. Nurse Education in Practice, 13: 262-270.

Yalın, H. (2004). Öğretim Teknolojileri ve Materyal Geliştirme. Nobel Yayın Dağıtım, Ankara. 